\title{
Preparation and characterization of coal gangue/Al cermet materials
}

\author{
Guihua $\mathrm{Wu}^{1, \mathrm{a}}$, Lihua Tang ${ }^{1}$ \\ ${ }^{1}$ School of Mechanical Engineering, North University of China, Taiyuan, Shanxi
}

\begin{abstract}
In this study, the calcined coal gangue was mixed with Al powder at different mass fractions ( $5 \mathrm{wt} \%$ $\sim 35 \mathrm{wt} \%$ ). After being pressed at $80 \mathrm{MPa}$ and sintered at $1200^{\circ} \mathrm{C}$ for $2 \mathrm{~h}$, the coal gangue/Al cermet material was obtained. The phase composition, microstructure and mechanical properties of the material were studied. The results show that the main components of the prepared materials are Al, mullite, AlN, alumina and silicon. With the increase of coal gangue powder, the hardness of coal gangue/Al cermet gradually increases, while the static compression strength first increases and then decreases. When the mass fraction of gangue is $25 \mathrm{wt} \%$, the coal gangue/Al cermet material has the best performance. Density is $2.23 \mathrm{~g} / \mathrm{cm}^{3}$, hardness is $752 \mathrm{HV}$, static compression strength is $127.3 \mathrm{MPa}$.
\end{abstract}

\section{Introduction}

These Coal gangue is a kind of solid waste which is separated in the process of coal production, and it increases and accumulates in large amount every year. It is estimated that China's coal gangue output will reach 729 million tons in 2020 [1]. At present, coal gangue is mainly used in filling materials and power generation, which have low utilization rate and low added value[2]. In order to solve the environmental problems caused by the accumulation of coal gangue, it is necessary to explore the efficient and high-value utilization of coal gangue. Through composition analysis, the main components of gangue removing organic impurities are $\mathrm{SiO}_{2}$ and $\mathrm{Al}_{2} \mathrm{O}_{3}$ $(>90 \%)$, which are the raw materials for preparing ceramics with excellent performance[3]. Therefore, the utilization of silica-alumina ceramic raw materials in coal gangue has become a research hotspot[4].

Cermet is a composite material consisting of a metal or alloy and one or more ceramic phases. Ceramics not only maintain the high hardness, wear resistance, corrosion resistance, high temperature resistance, oxidation resistance and chemical stability of ceramic materials, but also have high toughness and high thermal and electrical conductivity of metal materials[5,6]. The results show that adding ceramic particles into $\mathrm{Al}$ matrix can improve the strength, hardness, wear resistance and corrosion resistance[7,8]. At present, there are few studies on the preparation of coal gangue/Al cermet materials from coal gangue and $\mathrm{Al}$.

In this study, the preparation of coal gangue/Al cermet materials was carried out by using coal gangue removed organic matter as raw material and adding it into $\mathrm{Al}$ powder according to different mass fraction. Then the effects of different formulations on phase composition, mechanical properties and microstructure of gangue/Al cermet materials were explored.

\section{Materials and Characterization}

\subsection{Material preparation}

Coal gangue (Pingshuo Opencast Coal Mine, Shanxi, China)and Al powder (45um, 99.9\% purity, Zhongnuo New Material (Beijing) Technology Co., Ltd)as raw materials. The coal gangue is ground to micron level and calcined at $700^{\circ} \mathrm{C}$ for 2 hours to remove the organic matter. The calcined powder was placed in a ball-milling tank with the mass ratio of ball: powder: ethanol $=3: 1: 1$, and the powder was ball-milling for $3 \mathrm{~h}$ at $200 \mathrm{r} \cdot \mathrm{min}-1$. The milled powder was dried in a vacuum drying oven at $100{ }^{\circ} \mathrm{C}$ for $12 \mathrm{~h}$, and then sieved through a 200 mesh steel screen. The ball-milled powders were added into $\mathrm{Al}$ powder (45um) at different mass fractions $(5,15,25$, $35 \mathrm{wt} \%$ ) and mixed in a mixer for $2 \mathrm{~h}$. The mixed powder was put into a mold with a diameter of $12 \mathrm{~mm}$ and pressed into shape at $80 \mathrm{MPa}$ for $30 \mathrm{~min}$. The blank was placed in an alumina crucible and put into a Maeboiling furnace (model SX2-8-16) at a heating rate of $10^{\circ} \mathrm{C} \cdot \mathrm{min}-1$ to $1200^{\circ} \mathrm{C}$ for $2 \mathrm{~h}$. After cooling, it was taken out. The samples were polished on the metallographic polishing machine.

\subsection{Characterization}

BSA224S-CW electronic balance was used to measure the density. LEXT OLS4100 laser confocal microscope was used to observe the surface morphology. SmartLab-3KW $\mathrm{X}$-ray diffractometer was used to test the image

$\overline{{ }^{a} \text { Corresponding author:guihuawu_nuc@ } @ 163 . c o m ~}$ 
composition of sintered materials. The microstructure of the samples was observed by SU5000 scanning electron microscope. The Vickers hardness of ceramics was measured by DHV-1000 digital microhardness tester. CMT5105 universal testing machine was used to test the static compression strength.

\section{Results and discussion}

\subsection{Phase composition of coal gangue/Al cermet materials}

XRD patterns of coal gangue/Al cermet materials are shown in Fig. 1. Phase composition of coal gangue /Al cermet materials, the phase composition of cermet material is $\mathrm{Al}$ (PDF\#04-0787), mullite (PDF\#15-0776), AlN (PDF\#25-1133), alumina (PDF\#10-0173) and silicon (PDF\#37-1484). With the increase of coal gangue, the contents of AIN, alumina, mullite and silicon in the material increase with the increase of coal gangue, while the contents of $\mathrm{Al}$ decrease continuously. It is inferred that the Following chemical reaction occurred:

Mullite formation reaction:

$$
\begin{aligned}
& \mathrm{Al}_{2} \mathrm{O}_{3} \cdot 2 \mathrm{SiO}_{2} \cdot 2 \mathrm{H}_{2} \mathrm{O} \stackrel{450-550^{\circ} \mathrm{C}}{\longrightarrow} \mathrm{Al}_{2} \mathrm{O}_{3} \cdot 2 \mathrm{SiO}_{2}+2 \mathrm{H}_{2} \mathrm{O} \\
& 2\left(\mathrm{Al}_{2} \mathrm{O}_{3} \cdot 2 \mathrm{SiO}_{2}\right) \stackrel{>950^{\circ} \mathrm{C}}{\longrightarrow} \mathrm{Si}_{3} \mathrm{Al}_{4} \mathrm{O}_{12}+\mathrm{SiO}_{2} \\
& 3 \mathrm{Si}_{3} \mathrm{Al}_{4} \mathrm{O}_{12} \stackrel{>1050^{\circ} \mathrm{C}}{\longrightarrow} 2\left(3 \mathrm{Al}_{2} \mathrm{O}_{3} \cdot 2 \mathrm{SiO}_{2}\right)+5 \mathrm{SiO}_{2}
\end{aligned}
$$

Silicon formation reaction: $4 \mathrm{Al}+3 \mathrm{SiO}_{2} \stackrel{>860^{\circ} \mathrm{C}}{\longrightarrow} 3 \mathrm{Si}+2 \mathrm{Al}_{2} \mathrm{O}_{3}$

AlN formation reaction:

$2 \mathrm{Al}+\mathrm{N}_{2} \stackrel{>800^{\circ} \mathrm{C}}{\longrightarrow} 2 \mathrm{AlN}$

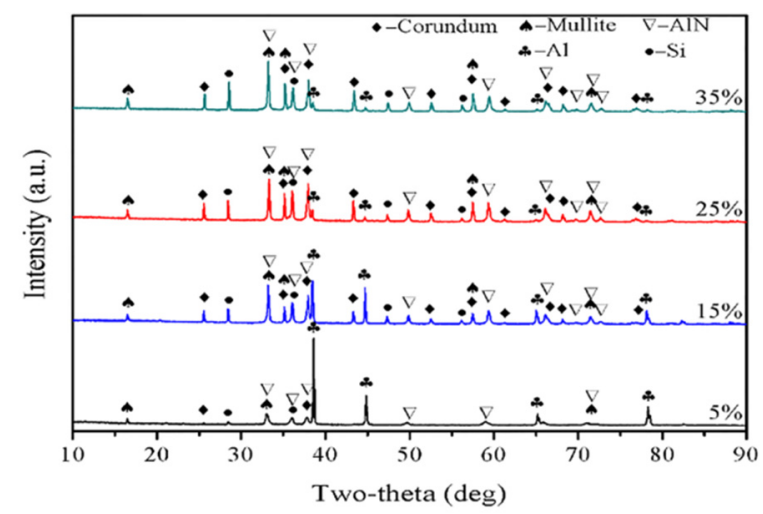

Figure 1. Phase composition of coal gangue /Al cermet materials.

It can be seen from XRD pattern that the sample with $5 \mathrm{wt} \%$ coal gangue generated less AIN than other samples. The reason may be that less coal gangue is added, and sufficient $\mathrm{Al}$ forms a dense oxide film on the surface of the sample, which prevents Al from further reacting with air.

\subsection{Density and surface morphology of coal gangue/Al cermet materials}

Table 1 shows the density of samples obtained by different formulations. With the addition of coal gangue, the density of samples gets lower and lower, mainly because the density of coal gangue is lower than Al. At the same time, there are a lot of pores in the sample, which will reduce the density.

Table 1. Density of Coal Gangue/Al Cermet Materials

\begin{tabular}{|c|c|}
\hline $\begin{array}{c}\text { Addition of } \\
\text { coal gangue } \\
\mathbf{w t} \%\end{array}$ & $\begin{array}{c}\text { Density } \\
\mathbf{g} / \mathbf{c m}^{\mathbf{3}}\end{array}$ \\
\hline 5 & 2.54 \\
\hline 15 & 2.41 \\
\hline 25 & 2.23 \\
\hline 35 & 2.05 \\
\hline
\end{tabular}

Fig. 2 shows the laser confocal micrograph of the sample surface with different formulas. It can be seen from the figure that there are black lumps in all samples, which is presumed to be ceramic strengthening phase. (a) There are a lot of scratches after grinding on the surface of the sample, and a small amount of black lumps exist on the surface. (b) There are still a few scratches after polishing on the surface of the sample, and there are a large number of black lumps. (c) scratches after grinding can hardly be observed on the sample surface, and black blobs are numerous and evenly distributed. (d) scratches after polishing were almost not observed on the surface of the sample. Compared with (c), there were more black masses and they were connected with each other.

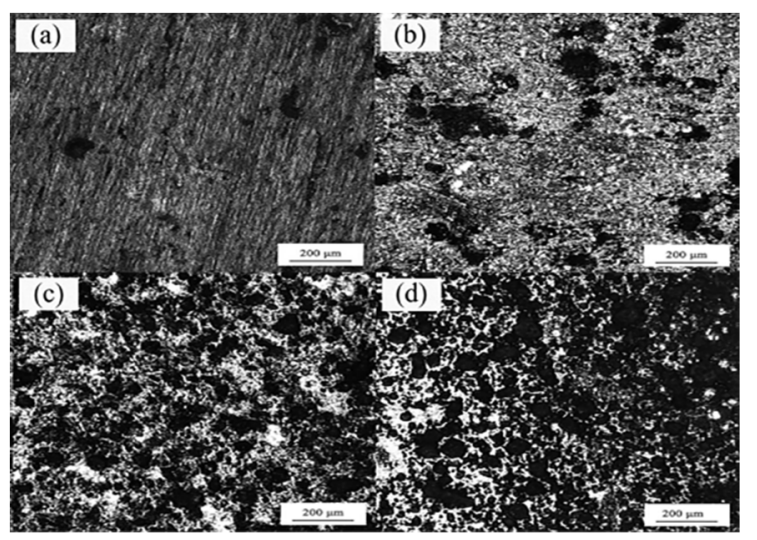

Figure 2. Surface topography of different formulations.

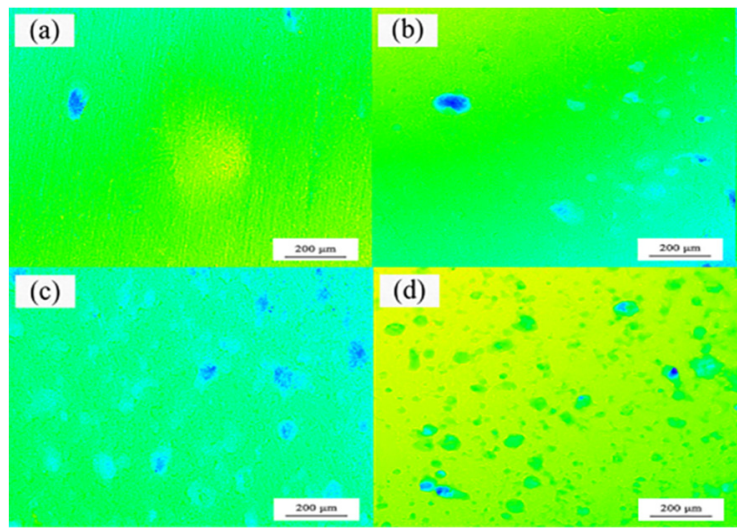

Figure 3. Surface heights of different formulations. Fig. 3 shows the surface heights of samples with 
different formulations. In the figure, each sample has surface depressing. Most of the samples do not show the deepest color in the pore's middle, but a combination of dark blue and light blue, suggesting that a network structure or other structures with different heights appear in the holes.

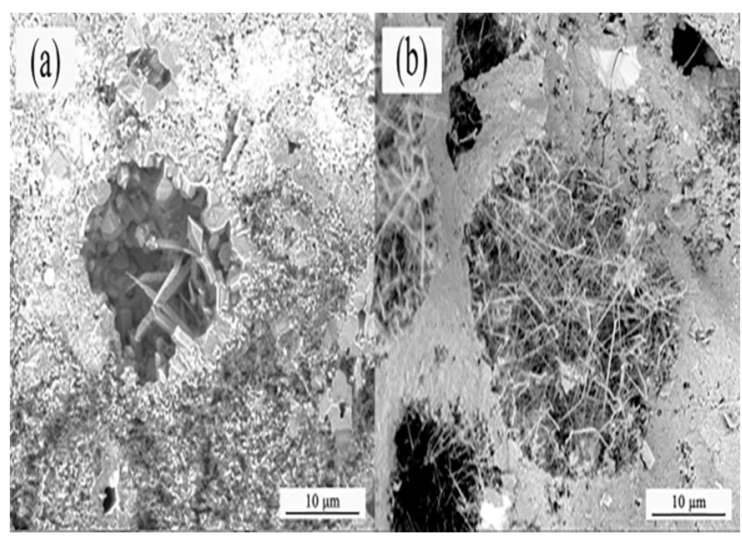

Figure 4. SEM of surface morphology.

By observing the SEM diagram of the sag area of each sample (Fig. 4), it can be found that most of the depressions have staggered columnar structures in (a) and interwoven reticular whiskers in (b).According to XRD analysis, the staggered columnar structure is mullite, and the interwoven network whiskers are AIN.

Table 2. Vickers hardness and static compression strength of Coal Gangue/Al Cermet Materials.

\begin{tabular}{|c|c|c|}
\hline $\begin{array}{c}\text { Coal gangue } \\
\text { /wt\% }\end{array}$ & $\begin{array}{c}\text { Vickers hardness } \\
\text { /Kg.mm-2 }\end{array}$ & $\begin{array}{c}\text { Static compression } \\
\text { strength /MPa }\end{array}$ \\
\hline 5 & 154 & 61.8 \\
\hline 15 & 513 & 89.6 \\
\hline 25 & 752 & 127.3 \\
\hline 35 & 723 & 109.1 \\
\hline
\end{tabular}

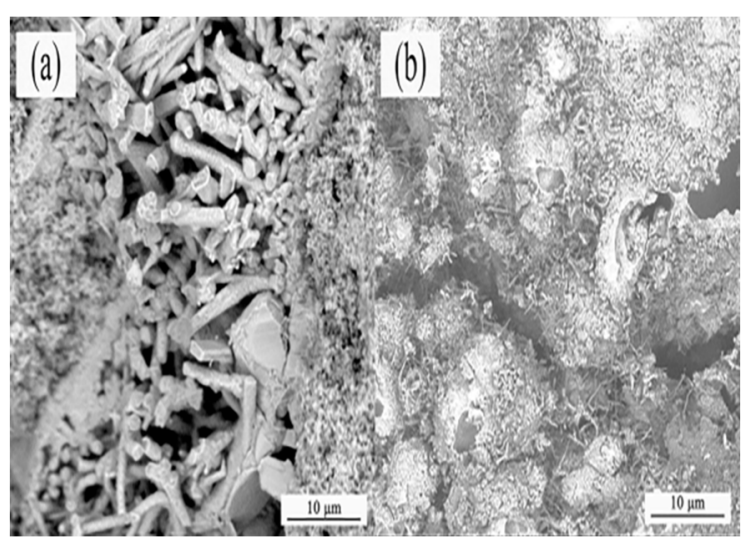

Figure 5. SEM of fracture surface.

\section{Mechanical properties and structure of coal gangue/Al cermet}

Table 2 shows the Vickers hardness and static compression strength of each sample. It can be seen that Vickers hardness increases with the increase of coal gangue, the reason is that the ceramic phase in the sample gradually increases, making the overall hardness of the material increase.

Among them, the Vickers hardness of the sample with $5 \mathrm{wt} \%$ coal gangue is much lower than that of other samples, because its main constituent phase is Al. Static compression strength is also significantly related to the amount of coal gangue added, in which it can be seen that the sample with $5 \mathrm{wt} \%$ coal gangue added is far less than the other three samples.

Through the SEM (Fig. 5) observation of the cross section of each formula sample, it was found that the columnar mullite and the AIN whisker were fractured, and the two structures increased with the increase of the addition amount of coal gangue. However, the sample with $25 \mathrm{wt} \%$ coal gangue is higher than that with $35 \mathrm{wt} \%$ coal gangue. It is inferred that the formation of a large amount of silicon will reduce the static compression strength of the sample.

\section{Conclusion}

1. When $25 \mathrm{wt} \%$ coal gangue is added, the material performance is the best. The prepared cermet materials has a density of $2.23 \mathrm{~g} / \mathrm{cm}^{3}$, a surface hardness of $752 \mathrm{HV}$ and a Static compression strength of $127.3 \mathrm{MPa}$.

2.Mullite can be formed from coal gangue at high temperature, and its interactive structure is beneficial to increase the compression resistance of cermet. At the same time, AlN whiskers formed by the reaction of $\mathrm{Al}$ and $\mathrm{N}_{2}$ in the air also play a strengthening role.

3. Coal gangue can be used as the raw material source of strengthening phase of cermet, which can improve the wear resistance of metal and further broaden the utilization area of coal gangue, so as to reduce the environmental pollution caused by coal gangue accumulation.

\section{References}

1. Li J , Wang J . Comprehensive utilization and environmental risks of coal gangue: A review[J]. Journal of Cleaner Production, 2019, 239:117946.

2. Dong Z G, Li P, Jia Y X, et al.Research progress on comprehensive utilization and resource treatment of coal gangue [J]. Environmental Protection Frontiers, 2021, 11(2):9.

3. Lü, Q K, Dong X, Zhu Z, et al. Environment-oriented low-cost porous mullite ceramic membrane supports fabricated from coal gangue and bauxite[J]. Journal of Hazardous Materials, 2014, 273:136-145.

4. Lou G H, Jin B, Jiang W G, et al.Preparation of foamed ceramics from coal gangue $[\mathrm{J}]$. Bulletin of Ceramics, 2020, v.39;No.283(04):276-280. 
5. Ru J J, He H.Preparation and research progress of ceramic particle reinforced metal matrix composites [J]. Science \& Technology Innovation and Application, 2019, 275(19):122-123.

6. Cai X L,Xu Y H,Zhong L S.Fracture toughness of WC-Fe cermet in W-WC-Fe composite by nanoindentation[J]. J.Alloy.Compd.,2017,728:788796.

7. Cong D L,Li Z S,He Q B.Wear behavior of corroded $\mathrm{Al}-\mathrm{Al}_{2} \mathrm{O}_{3}$ composite coatings prepared by cold spray[J]. Surf.Coat.Tech.,2017,326:247-254.

8. Han Q,Geng Y,Setchi R.Macro and nanoscale wear behaviour of $\mathrm{Al}-\mathrm{Al}_{2} \mathrm{O}_{3}$ nanocomposites fabricated by selective laser melting[J].Comp.Part B Eng.,2017,127: 26-35. 